Rev Biomed 2001; 12:130-136.

\title{
¿Pueden los mosquitos transmitir el virus de la inmunodeficiencia humana?
}

Revisión

Guadalupe Ayora-Talavera ${ }^{1}$, Pablo C. Manrique-Saide ${ }^{2}$.

${ }^{1}$ Centro de Investigaciones Regionales "Dr. Hideyo Noguchi”. ${ }^{2}$ Facultad de Medicina Veterinaria y Zootecnia. Universidad Autónoma de Yucatán, Mérida, Yucatán, México.

\section{RESUMEN.}

La transmisión del virus de la inmunodeficiencia humana (VIH) se conoce ocurre por contacto sexual, perinatalmente, y por exposición a sangre infectada o productos sanguíneos entre otros. Preguntarse si existe la posibilidad de transmisión del VIH por insectos hematófagos de personas infectadas a personas no infectadas ha sido y es un punto de intensa discusión. Las rutas clásicas de transmisión de patógenos por artrópodos chupadores de sangre son "mecánica" o "biológica". Ambas rutas son rechazadas, la última porque no existe replicación de retrovirus en el vector y su sobrevivencia en el artrópodo es muy limitada. La persistencia del VIH en un insecto o en sus partes bucales es uno de los numerosos factores necesarios para la transmisión mecánica en la naturaleza. El riesgo de transmisión del VIH por insectos parece ser extremadamente bajo o inexistente. En este artículo de revisión se exponen las razones y evidencias científicas que nos permiten concluir porque la transmisión del virus VIH por mosquitos no es posible.

(Rev Biomed 2001; 12:130-136)

Palabras clave: VIH, SIDA, transmisión del VIH, vectores, mosquitos.

\section{SUMMARY.}

Can mosquitoes transmit Human Immunodeficiency Virus?

Transmission of human immunodeficiency virus (HIV) is known to occur perinatally, through sexual contact, and after exposure to infected blood or blood products among others. The question whether the possibility exists of transmission of HIV by hematophagous insects from infected to uninfected persons is a point of very intensive discussion. The classical routes of pathogen transmission by blood-sucking arthropods are either "mechanical" or "biological". Both ways are

Solicitud de sobretiros: M. en C. Guadalupe Ayora-Talavera, Centro de Investigaciones Regionales "Dr. Hideyo Noguchi·", Universidad Autónoma de Yucatán, Ave. Itzáes No. 490 x 59, C.P. 97000, Mérida, Yucatán, México. E- mail: talavera@tunku.uady.mx.

Recibido el 14/Febrero/2000. Aceptado para publicación el 5/Septiembre/2000. 
G Ayora-Talavera, PC Manrique-Saide.

rejected, the latter since no replication of the retroviruses in the vector exists and its survival in the arthropod is very limited. The persistence of $\mathrm{HIV}$ in an insect or on its mouthparts is one of many factors necessary for mechanical transmission in nature. The risk of insect transmission of HIV appears to be extremely low or non-existent. This reviews article summarise the scientific evidence and reasons to conclude why HIV transmission by mosquitoes is impossible.

(Rev Biomed 2001; 12:130-136)

Key words: HIV, AIDS, HIV transmission, vectors, mosquitoes.

\section{INTRODUCCIÓN.}

La mayoría de los mosquitos son hematófagos, es decir, que se alimentan de sangre. La sangre de los vertebrados contiene nutrientes, especialmente aminoácidos esenciales, necesarios para la maduración de sus huevos (1). Para nuestra fortuna, las diferentes especies de mosquitos varían ampliamente en sus preferencias por los hospederos y son selectivos en sus fuentes de alimento, por lo que sus molestias se distribuyen entre casi todas las especies de vertebrados terrestres (2).

La transmisión de algunas enfermedades virales que afectan a los seres humanos u otros animales, son el resultado del hábito hematófago de los mosquitos, como es el caso del virus del dengue que es transmitido por la picadura del mosquito Aedes aegypti. Este virus es uno de los más de 200 que han sido aislados en otras especies de mosquitos (3).

El virus de la inmunodeficiencia humana (VIH), agente causal del síndrome de inmuno deficiencia adquirida humana (SIDA), ha adquirido gran importancia en salud pública dada la alta frecuencia de individuos infectados (30.6 millones hasta diciembre de $1997 \mathrm{y}$ se estima que 40 millones para el año 2000 de acuerdo a ONUSIDA) y por los mecanismos, ya sean biológicos o mecánicos, a través de los cuales es transmitido.
Desde el inicio de la epidemia de VIH y SIDA, ha existido la preocupación por la posibilidad de transmisión de virus por picaduras de mosquitos y a pesar que este tema fue abordado durante los años ochenta y ha sido discutido en numerosos textos científicos de diverso nivel (4-7), sigue siendo una creencia en muchos países en donde se han llevado a cabo encuestas de actitudes, conocimientos y prácticas sobre el VIH en fechas recientes. Sólo a manera de ejemplos, un tercio de estudiantes de preparatorias y universidades en Papua Nueva Guinea (8) y el $86 \%$ de estudiantes en una localidad del sur de la India (9), contestaron en encuestas, creer que los mosquitos transmiten VIH.

Más aún, sigue siendo una de las preguntas más frecuentes para aquellos que trabajamos con virus y con insectos y a menudo es tarea de reuniones familiares o de amigos tratar de responder las preguntas que giran en torno a la suposición: si el virus VIH es transmitido por la aguja de una jeringa, ¿no puede ser transmitido por la picadura de un mosquito?. De manera concluyente nuestra respuesta siempre ha sido una negación. Sin embargo, en esta ocasión queremos mencionar algunas de las razones y evidencias científicas que justifican este "no", y que a fin de cuentas para todos, es agradable escuchar.

\section{HISTORIA DE UN RUMOR: EL CASO BELLE GLADE.}

La información en los medios concernientes a la probabilidad de transmisión de VIH por mosquitos fueron comunes desde el inicio de la enfermedad. El tópico dio inicio cuando después de la primera conferencia internacional de SIDA, se mencionó que en una pequeña comunidad en el sur del estado de Florida, Belle Glade, había evidencia preliminar de que los mosquitos podían ser responsables de un aumento en el promedio de la incidencia de SIDA en una población local $(10,11)$.

En esta tristemente "famosa" localidad, Whiteside y colaboradores encontraron que $20 \%$ de los habitantes infectados con VIH aparentemente no presentaban factores de riesgo asociados con

\section{Revista Biomédica}


la transmisión del virus. Estos investigadores hicieron énfasis en la presencia de varios factores ambientales, entre ellos, criaderos altamente productivos de mosquitos. Sin embargo, nunca se mencionó específicamente la posibilidad de transmisión de VIH por mosquitos. Este trabajo fue mal dirigido y se vio reforzado cuando un investigador, Jonathan Mann, que fue en alguna ocasión director del programa de SIDA de la OMS, comentó en un seminario que observaciones en ciertas comunidades de Zaire le hacían pensar en la probabilidad de la transmisión del VIH por artrópodos y que merecía mayor investigación (12).

\section{MECANISMOS DE TRANSMISIÓN DEL VIRUS VIH.}

Entre los principales mecanismos de transmisión del VIH se encuentran: 1) transmisión sexual de hombre a mujer, de mujer a hombre y de hombre a hombre; 2) transmisión vertical (trasplacentaria, durante el parto y por leche materna); 3) iatrogénica, a través de sangre, productos sanguíneos y trasplantes (córnea, riñón); 4) por drogadicción intravenosa y 5) piquetes accidentales con agujas infectadas.

El VIH es un miembro de la familia Retroviridae, nombre que ha sido asignado por la propiedad que poseen de transformar su material genético estructurado como ácido ribonucléico (ARN) en ácido desoxiribonucléico (ADN) gracias a una enzima del virus llamada transcriptasa reversa y que les permite de esta manera integrarse al material genético de la célula hospedera. Como paso inicial en el proceso de infección del VIH es necesaria la interacción del virus con moléculas específicas del hospedero llamadas receptores. Una vez que este proceso ha ocurrido, el virus es capaz de liberar dentro del hospedero su material genético, en este caso ARN (13).

Algunas personas temen que el VIH pueda ser transmitido por otras vías; sin embargo, no hay evidencia que de soporte a esos temores. $\mathrm{Si}$ el VIH fuese transmitido por otras rutas como el aire o mosquitos, el patrón de los reportes de casos de infección de VIH, sería muy diferente al observado, y muchos casos serían reportados en personas con ningún factor de riesgo asociado o identificado.

\section{TRANSMISIÓN DE VIRUS A TRAVÉS DE MOSQUITOS EN HUMANOS.}

Un mosquito u otro organismo que transmite un agente patógeno se denomina de manera general como un vector. Existen dos mecanismos básicos a través de los cuales un mosquito puede ser vector de virus para el humano y que difieren en cuan "esencial" es el mosquito en el proceso de diseminar los organismos infecciosos. El primero, conocido como transmisión biológica, ocurre cuando el virus es ingerido con la sangre de una persona infectada, se reproduce y multiplica (replicación) en el insecto, migra hacia las glándulas salivales y es transferido a personas no infectadas de las cuales el mosquito se alimentará después (14). Esta es la manera como los virus del dengue o la fiebre amarilla son transmitidos por el mosquito Aedes aegypti.

El segundo mecanismo a través del cual un mosquito u otro insecto hematófago pueden transmitir virus es conocido como transmisión mecánica. El insecto debe comenzar a alimentarse de una persona infectada con virus y ser interrumpido por una razón u otra. En lugar de regresar a su hospedero original, el insecto se moverá hacia otra persona no infectada, para completar su alimento. El insecto transferirá el virus dentro de la sangre fresca que permanece en sus partes bucales de su previo hospedero al nuevo y regurgitará también algo de su previo alimento (15).

\section{ESCENARIOS HIPOTÉTICOS PARA LA} TRANSMISIÓN DE VIH POR MOSQUITOS.

A partir de estos dos mecanismos, los escenarios en los que un mosquito podría verse involucrado en la transmisión del VIH son los siguientes: 


\section{G Ayora-Talavera, PC Manrique-Saide.}

\section{Caso I: transmisión biológica del VIH por mosquitos.}

En el primer mecanismo, un mosquito tendría que iniciar el ciclo alimentándose de un individuo VIH-positivo e ingerir las partículas virales con la sangre. Para que el virus sea transmitido, debe sobrevivir dentro del mosquito, preferentemente incrementar su número y luego migrar a las glándulas salivales. El mosquito infectado deberá entonces buscar y alimentarse de nuevo de una persona no infectada y transferir el VIH de sus glándulas salivales durante el transcurso de la picadura.

¿Por qué esta hipótesis no es posible? Sabemos que la supervivencia del virus está relacionada con la cantidad de virus ingerido inicialmente. Se ha observado, que cuando se alimenta a mosquitos con dosis desde 1,000 a 100,000 unidades infecciosas por $\mathrm{mL}$ de cultivo $\left(10^{4}-10^{5} / \mathrm{mL}\right)$, el VIH no sobrevive en los mosquitos (16). No obstante se ha observado que en mosquitos inoculados intratorácicamente con una dosis de un millón de unidades de VIH por $\mathrm{mL}$ de cultivo, éste último puede sobrevivir hasta 48 horas. No hay evidencia de que el VIH se multiplique en mosquitos, es más, no se sabe que el virus produzca enfermedad en otro ser vivo, así que está limitado a humanos.

En humanos el VIH tiene afinidad por linfocitos T-cooperadores y se une a la molécula CD4 que caracteriza este grupo de células T especificas. En experimentos $(7,17)$ se ha observado que el VIH sí puede unirse a ciertos tipos de células de mosquito o al menos está presente, aún careciendo del receptor CD4. No obstante que el VIH se detectó en el genoma de insectos, fue imposible saber que células y cuantas de ellas contenían las secuencias virales, lo que se consideró un artefacto de los métodos.

Uno de los trabajos más importantes que creó gran controversia en los resultados y "morbo" en aquel entonces, fue el realizado por Chermann y col. (18) quienes encontraron secuencias homólogas del ADN de VIH en insectos, incluyendo mosquitos, en Africa Central. No obstante, los hallazgos eran poco claros al encontrarse en mosquitos machos, cucarachas y hormigas león. Los autores propusieron en aquel entonces que la presencia de secuencias similares a VIH se debía a otros retrovirus integrados al genoma de los insectos en previas generaciones. Otros autores se han cuestionado si estos hallazgos fueron resultado de reacciones no específicas o cruzados con otros virus de ARN $(7,18)$.

Sin embargo, en ninguno de los casos se presentó evidencia de virus libre o replicación dentro de los mosquitos. Así que aunque el VIH pueda unirse o estar presente en el genoma de mosquitos, no se replica en las células (19).

De cualquier modo, aunque el virus sea detectable por un periodo de tiempo, finalmente desaparece y la concentración nunca aumenta, lo que evidencia la ausencia de replicación.

\section{Los mosquitos no son simples jeringas "voladoras". \\ Mucha gente piensa en los mosquitos como} jeringas minúsculas, y por ende, si las jeringas pueden infectar un individuo con VIH a partir de otro individuo, entonces los mosquitos deben ser capaces de hacer lo mismo.

En su intento por alimentarse, los artrópodos hematófagos encaran problemas tanto de naturaleza mecánica como farmacológica. Primero, la sangre no es muy abundante en la piel de la mayoría de los vertebrados. Localizar los vasos sanguíneos en la piel, es una habilidad formidable debido a que en la mayoría de los casos el hospedero tiende a interrumpir la alimentación o matar al insecto. Para ser exitoso, los mosquitos deben comportarse no sólo como flebotómidos, sino también como farmacólogos (20).

Un mosquito dista mucho de ser considerado una simple jeringa infecciosa. Para que un virus sea transmitido por un mosquito, debe pasar por muchos pasos (figura 1). El virus deberá ser primero ingerido por el mosquito. Una vez en el interior del mosquito, el virus deberá evitar el paso

\section{Revista Biomédica}


por el divertículo donde se almacenan el néctar y los azúcares, para pasar al intestino medio del insecto en donde de inmediato se verá en un ambiente hostil creado por enzimas digestivas y la presión de una envoltura alrededor de la sangre ingerida, la membrana peritrófica, creada por el intestino del insecto. Del intestino medio tiene que salir del lumen hacia la cavidad corporal antes de que la digestión lo inactive o sea expelido por el ano. Si bien lograra escapar a estas barreras, deberá penetrar las células de la pared del intestino, encontrar una célula en el mosquito para infectarla y replicarse.

Los arbovirus, por lo general, se replican con éxito en las células del insecto. Sin embargo, para el caso del VIH, además de que es necesario que la célula posea los receptores específicos para que esta sea infectada y el virus sea capaz de liberar su ARN, se requiere que el ARN viral sea transformado en ADN e integrarse al material genético de la célula hospedera.

Si el VIH lograra replicarse exitosamente,

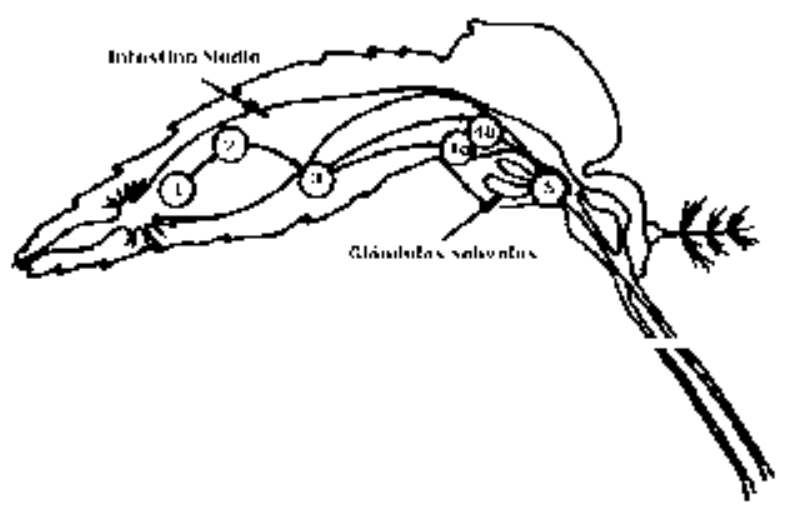

Figura 1.- Secuencia requerida para que un mosquito hembra transmita un arbovirus después de ingerir sangre infectada. 1) Sangre infectada ingerida; 2) El virus se multiplica en las células epiteliales del intestino medio; 3) El virus es liberado de las células; 4a) El virus infecta las glándulas salivales después de amplificarse; 4b) El virus infecta las glándulas salivales sin amplificación; 5) El virus es liberado de las células epiteliales de las glándulas salivales y transmitido en la picadura. Tomado de Referencia 22. los nuevos viriones deben ser liberados en una cantidad adecuada a la cavidad corporal de los insectos, el hemocele, bañada por la hemolinfa, que hace la vez de sangre en los insectos, para subsecuentemente circular e infectar las glándulas salivales. No obstante, en la hemolinfa, los virus estarán expuestos de nuevo a otro ambiente hostil: el sistema inmune de los insectos.

Una vez infectadas las glándulas salivales, los virus deben de concentrarse en una cantidad adecuada, para que cuando el insecto produzca saliva y se alimente, sean inoculados directamente a un hospedero humano.

\section{Caso II. transmisión mecánica del VIH por mosquitos.}

En el segundo mecanismo, un mosquito tendría que iniciar el ciclo alimentándose de un individuo VIH-positivo y ser interrumpido antes de terminar su alimentación. Entonces, en vez de digerir la alimentación parcial de su hospedero original, el mosquito tendría que buscar y alimentarse de nuevo de una persona no infectada para completar su alimentación. Al penetrar la piel del nuevo hospedero, el mosquito transferiría partículas virales que quedaron adheridas a las partes bucales en la previa alimentación.

¿Qué hace que esta hipótesis se rechace? La máxima cantidad teorética que puede ser transmitida será la cantidad ingerida. Se ha observado que en tábanos es $0.001 \times 10^{-2} \mathrm{~mL}$ de sangre residual $(15,21)$. Si consideramos que sólo el $10 \%$ de la sangre es depositada, entonces será de un orden de magnitud de $10^{-6}$ a $10^{-5} \mathrm{~mL}(0.0001$ x $10^{-2}$ a 0.0001 x $10^{-2} \mathrm{~mL}$ ).

También, la transmisión mecánica depende de la cantidad de virus inyectado a una persona sana, que depende a su vez de la cantidad de virus ingerida por el insecto y presente en las partes bucales, la concentración de virus en la sangre y que sea absorbida, del número de picaduras de insectos infectados con VIH y de la prevalencia de enfermos en la población que está en el rango de los insectos pero que interrumpen su alimentación. 


\section{G Ayora-Talavera, PC Manrique-Saide.}

Otros factores a considerar son el intervalo de tiempo entre las picaduras y la cantidad de virus que queda en las partes bucales y que será inyectada.

\section{LA CANTIDAD HACE UNA DIFERENCIA.}

En las enfermedades transmitidas por insectos que tienen la habilidad de ser transmitidas de un individuo a otro mecánicamente, los agentes patógenos circulan en altos niveles en la sangre del hospedero. La transferencia por partes bucales contaminadas requiere un número suficiente para crear una nueva infección. El número exacto de partículas infectivas varía de una enfermedad a otra. El VIH circula a muy bajos niveles en la sangre incluso en personas con carga viral alta, mucho más abajo que cualquier otro agente patógeno transmitido por mosquitos. En los individuos infectados rara vez circulan más de $10 \mathrm{U} / \mathrm{mL}$ de sangre de VIH, y entre 70 y $80 \%$ de las personas infectadas con VIH tiene niveles indetectables de partículas virales en su sangre. Los cálculos con mosquitos y VIH, son que un mosquito que es interrumpido en su alimentación de un hospedero con 1000 unidades de VIH circulando, tiene una probabilidad de 1:10 millones de inyectar una unidad de VIH a una persona libre de infección por este virus.

Esto significa que un individuo sano y seronegativo tendría que ser picado por 10 millones de mosquitos que se hayan alimentado de un paciente VIH positivo para que se de la probabilidad de recibir una unidad de VIH de las partes bucales contaminadas de un mosquito. Es decir que, aún cuando esto fuera posible, sería una probabilidad muy remota. Sólo a manera de comparación, la probabilidad de que nos caiga un rayo es de 1:600,000, así que podemos decir que es más fácil que nos caiga un rayo a que lo otro ocurra. Tal y como mencionaron alguna vez nuestros colegas Piot y Schofield (1986) y considerando los grupos de edad (> de 14 años) y de riesgo (hombres homosexuales y prostitutas) en donde se observa la mayor prevalencia de VIH, sería difícil de imaginar un mosquito que tuviera preferencia en alimentarse de homosexuales y prostitutas y que evadiera a niños entre 4 y 14 años. Por todo esto, estamos seguros que el VIH no es transmitido por mosquitos.

\section{REFERENCIAS.}

1.- Dimond JB, Lea AO, Hahnert WF, de Long DM. The amino acids required for egg production in insects. Proceedings of the Tenth International Congress of Entomology, Montreal, Canada 1956; 2: 135-137.

2.- Hocking B. Blood-sucking behaviour of terrestrial arthropods. Ann Rev Entomol 1971; 16: 1-26.

3.- Leake CJ. Arbovirus-mosquito interactions and vector specificity. Parasit Today 1992; 8: 123-128.

4.- Piot P, Schofield CJ. No evidence for Arthropod transmission of AIDS. Parasit Today 1986; 2: 294.

5.- Booth, W. AIDS and insects. Science 1987; 237: 3556.

6.- Leishman K. AIDS and insects. The Atlantic Monthly 1987; Sept: 56-72.

7.- Miike L. Do insects transmit AIDS? In: AIDS related issues. Health Program Office of Technology Assessment United States Congress. Washington, D.C. 1987; 1-43.

8.- Friesen H, Danaya R, Doonar P, Kemiki A, Lagani W, Mataio G, et al. Assessment of HIV/AIDS knowledge, attitudes and behaviour of high school students in Papua New Guinea. PNG Med J 39: 208-13.

9.- Ambati BK, Ambati J y Rao AM. Dynamics of knowledge and attitudes about AIDS among the educated in southern India. AIDS Care 1997; 9: 319-30.

10.- Whiteside ME, Withum D, Tavris D, MacLeod C. Outbreak of no identifiable risk acquired immunodeficiency syndrome (AIDS) in Belle Glade, Florida. First International Conference on AIDS. Atlanta April $17^{\text {th }}$, E.U.A 1985.

11.- Castro KG, Lieb S, Jaffe HW, Narkunas JP, Calisher $\mathrm{CH}$, Bush TJ, et al. Transmission of HIV in Belle Glade, Florida: Lessons for other communities in the United States. Science 1988; 239: 193-7.

\section{Revista Biomédica}


12.- Mann JM, Francis H, Quinn T. Surveillance for AIDS in a Central Africa city: Kinshasa, Zaire. JAMA 1986; 255 : 3255-9.

13.- Coffin JM. Retroviridae and their replication, En Fields BN, Knipe DM eds. Fields Virology. New York: Raven Press; 1999. p. 961-1034.

14.- Langley PA. Pathogen transmission in relation to feeding and digestion by haematophagous arthropods. Acta Trop XXXII 1975; 2: 116-23.

15.- Foil LD, Issel J. Transmission of retroviruses by arthropods. Annu Rev Entomol 1991; 36: 355-81.

16.- Jupp PJ, Lyons SF. Experimental assesment of bedbugs (Cimex lenticularis and Cimex hemipterus) and mosquitoes (Aedes aegypti formosus) as vectors of human immunodeficiency virus. AIDS 1987; 1: 171-4.

17.- Becker JL, Hazan U, Nugeyre MT, Rey F, Spire B, et al. Infection of insect lines by HIV, agent of AIDS, and evidence for HIV proviral DNA in insects. CR Acad Sci Paris 1986; 303: 303-6.

18.- Chermann JC, Becker JL, Hazan U, et al. HIV related sequences in insects from Central Africa. $3^{\text {rd }}$ International Conference on AIDS. Washington D.C. E.U.A. June $1^{\text {st }}$, 1987.

19.- Srinivasan A, York D, Bohan C. Lack of HIV replication in Artrhopod cells. Lancet 1987; 1:1094-5.

20.- Ribeiro JMC. Blood-feeding arthropods: live syringes or invertebrate pharmacologists?. Infect Agents Dis 1995; 4:143-52.

21.- Foil LD. Tabanids as vectors of disease agents. Parasit Today 1987; 5: 88-96.

22.- Hardy JL. Susceptibility and resistance of vector mosquitoes. In: Monath TP, ed. The arboviruses: ecology and epidemiology, Vol I. Boca Raton: CRC Press; 1988. p. 87-126. 